\title{
Review of Effective Thermal Conductivity of Rock-Soil for Geothermal
}

\author{
Energy Applications
}

\author{
G.S. Jia ${ }^{1}$, Z.Y. Tao ${ }^{1}$, X.Z. Meng ${ }^{1}$, C.F. $\mathrm{Ma}^{1}$, J.C. Chai ${ }^{2 *}$, L.W. Jin ${ }^{1 *}$ \\ ${ }^{\prime}$ Group of Building Environment and Sustainable Technology, School of Human Settlements and Civil Engineering, Xi'an \\ Jiaotong University, Xi'an 710049,China. \\ ${ }^{2}$ Department of Engineering and Technology, School of Computing and Engineering, University of Huddersfield, Huddersfield, \\ HD1 3DH, UK \\ Corresponding authors: j.chai@hud.ac.uk; lwjin@xjtu.edu.cn
}

\begin{abstract}
The utilization of geothermal energy through ground buried heat exchanger to provide heat source for buildings has become extremely attractive recent years in China and all over the world. As a key parameter that governs the prediction of the system performance, the effective thermal conductivity of the ground significantly affects the heat transfer process between buried pipes and surrounding rock-soil. This paper conducts a review on the methods of determining the effective thermal conductivities of different rock-soil types composed by various substances proposed in recent years. Based on the analysis of theoretical methods and experimental approaches applied to different rock-soil conditions and other relevant parameters such as the porosity, water content and material construction, etc., the applicabilities of various methods have been justified. According to the deficiencies of basic models, the improved models take into account the effects of the temperature, saturation degree, detailed structure of rock-soil and other parameters to improve the accuracy of prediction value. For certain types of rock-soil, the experimental approaches can provide more accurate results but are expensive and time consuming, which have sometimes been used to improve the accuracy or verify the results of improved model in the appropriate range of porosity and saturation degree for certain types of rocks. The concluding remarks would contribute to the estimation of the heat transfer performance of the buried heat exchanger during the prediction process.
\end{abstract}

Key words: Geothermal energy; Effective thermal conductivity; Rock-soil; Theoretical methods; Experimental methods 


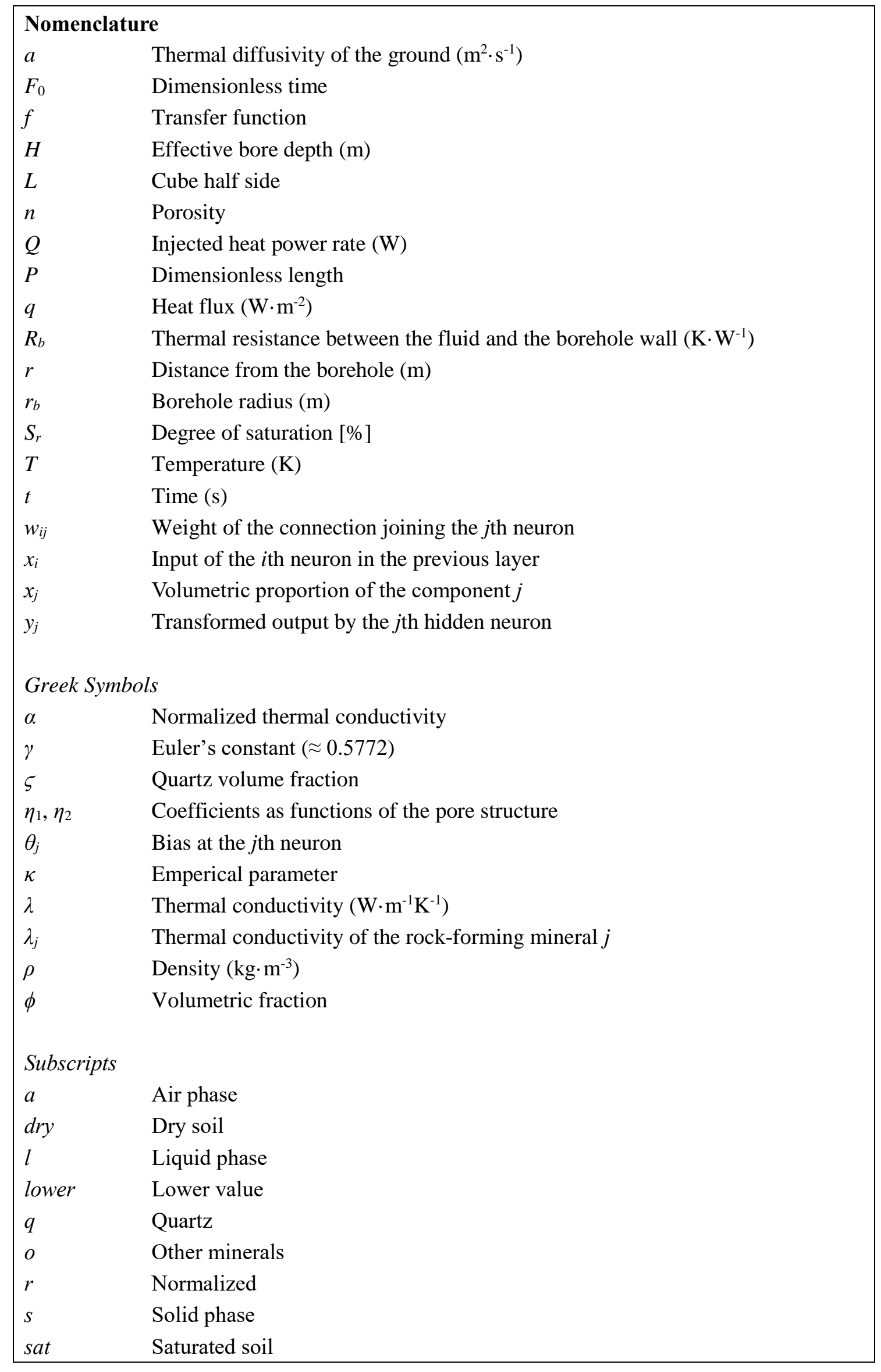




\begin{tabular}{|ll|}
\hline ug & Undisturbed \\
upper & Upper value \\
$\Delta$ & Differential \\
& \\
Superscript & \\
$*$ & Reference value \\
\hline
\end{tabular}

\section{Introduction}

The worldwide energy crisis calls for the need to use the renewable energy, such as the geothermal energy, which has taken greater importance than before. In general, different types of pipes are placed underground at certain depth to absorb heat from the rock-soil. The heat transfers from the high temperature rock-soil through the pipe wall of the exchanger to the working fluid inside the pipe. The fluid continuously circulates between the buried pipe and the system above the ground section, carrying heat from the ground to the thermal equipment for further use.

There are many factors that may affect the performance of the above mentioned system, including the climate, structure and material of the buried pipe, the flow rate and parameters of the working fluid, thermal properties of the ground, etc. The structure and material of the buried pipe mainly influence the costs of the system. The flow rate and parameters of the working fluid determine the pumping power and can be adjusted according to the requirements during operating process. The climate may have impact on the shallow layer temperature of the ground. Among these factors, the effective thermal conductivity of the ground is an important factor in terms of heat transfer between the external wall of the buried pipe and the ground as well as the heat conduction in soil, which dominates the heat exchange potential of the whole system during operating process. It can be seen from Fourier's law of heat conduction that the heat transfer area and temperature gradient, together with the thermal conductivity determine the amount of heat exchange in a conduction process. Once the position and structure of the pipe (including inner and outer diameters, length, and thermal properties) are determined, the first two terms become constant values and are not difficult to acquire. When the heat exchange system starts running, the temperature distribution of the rock-soil changes continuously. This would in turn affect the 
performance of the system. According to the line source theory, in the surroundings of the borehole, the temperature distribution can be expressed as (Morgensen, 1983),

$$
T(r, t)=T_{\text {ug }}-\frac{Q}{4 \pi \lambda} E i\left(-\frac{r^{2}}{4 a t}\right)
$$

where $T(r, t)$ is the temperature of the rock-soil at distance $r$ from the borehole after $t$ seconds running, $T_{u g}$ is the undisturbed ground temperature, $Q$ is the heat flow per unit length, $E i$ represents the exponential integral and $a$ is the ground thermal diffusivity. It is evident that the temperature of the rock-soil at the certain position and time is dominated by the thermal conductivity of the rock-soil, which influences further the temperature difference between the borehole and the ground, therefore affects the prediction of the system performance. Thus, it is a crucial problem to definitude the thermal conductivity of the ground. Besides, the thermal conductivity of the rock-soil is essential for the optimal design of the buried heat exchange system because it determines the heat exchange per unit length of the borehole, and consequently affects the minimum length of the buried pipe and the installation costs (Fujii et al., 2009). Kavanaugh (2000) stated that 10\% variation in the test of thermal conductivity could lead to $4.5 \% \sim 5.8 \%$ design error of the borehole depth. The more accurate information on the rock-soil properties are acquired, the more costs can be saved by allowing the length of the ground buried pipe to be reduced (Hwang et al., 2010).

Generally speaking, the thermal conductivity of porous rock-soil is affected by various physical properties including the density, porosity, volumetric proportion of components, grain size, saturation ratio and so on. The structures and properties of the rock-soil at different positions and different depth differ distinctly from one another. Even at the same depth, the nearby rocks may also show disparate thermal properties due to the change of geological structure. Extensive research has been conducted to estimate the ground properties through theoretical methods and experimental approaches based on reasonable simplifications. Rees et al. (2000) conducted a review of the ground heat transfer effects on the thermal performance of the ground buried heat exchangers. They introduced the mechanisms of ground heat transfer and presented an overview of the methods available to solve the heat transfer problem 
during the design process, before they gave the methods of estimating the thermal properties of the soils. They introduced the expression forms of theoretical models including the parallel model, weighted arithmetic mean method, weighted arithmetic mean equation, weighted geometric mean method, De Vries model (Vires et al., 1963) and Van Rooyen and Winterkorn's model (based on the original work of Nusselt (1916) on the thermal conductivity calculation) (Van and Winterkorn, 1957). Makowski and Mochlinski's method (Makowski and Mochlinski, 1956) as well as Thomas' method (Thomas et al., 1994) were also mentioned as empirical equations. The authors briefly described the meaning of different parameters in the equations and the applicability of the above methods before introducing the solutions on solving the ground heat transfer equations.

Wang and Pan (2008) made a review on the challenges and difficulties in the prediction of complex multiphase materials and theoretical models to calculate the thermal conductivity. The main difficulties in studying the properties of multiphase materials came from their inherent variety, randomness, as well as the coupling between the components of different phases. The authors divided the existing thermal conductivity models into two parts. The wo-component models, including the series and parallel models, network models (decomposing complex microstructure of multiphase material into a network consisting of a set of series and parallel elements) (Agari and Uno, 1986; Bouguerra, 1999; Lehmann et al., 2003; Liang and Ji, 2000; Staggs, 2002; Yu and Li, 2006; Liang and Qu, 1999) and theoretical bounds (upper and lower bounds of the thermal conductivity) (Hashin, 1983; Hashin and Shtrikman, 1963; Zimmerman, 1992; Schapery, 1968;) were analyzed. Multiphase cases (mainly for the unsaturated soils) included empirical equations (connect the fractions of multiphase components with experimental data) (Cosenza et al., 2003; Friedman, 2005; Miyamoto et al., 2003; Batchelor and O'brien, 1977; Alharthi and Lange, 1987), modified mixing models (directly extend the two-component model to multiphase cases or treat the multiple phases as one single phase) (Woodside and Messmer, 1961; Dobson et al., 1985) and analytical solutions from the physical laws (replace the actual structure with certain model for simplification) (Friedman, 1998; Dagan, 1989; Tinga et al., 1973; Miyamoto et al., 2005; Gori and Corasaniti, 2003). The authors noted that the capability of the existing theoretical models 
to predict the effective properties was greatly limited because they were based on simplified physics with over-idealized assumptions. Efforts in combining models with complex structures or measurement data might lead to improving the accuracy of the models but would narrow their applicability. Besides, the numerical methods and experimental results were also presented to compare with the theoretical prediction results.

Dong et al. (2015) did a review on the thermal conductivity models for the unsaturated soils. They concluded that the thermal conductivities of the rock-soil were governed by the factors including the mineralogy, particle size, particle shape, packing geometry, stress level, water content, porosity, gradation and cementation, which could be further generalized into the following elements: thermal conductivity of different constituent, type of soil, water content and particle contact. They categorized the existing models into three groups based on their principles. Mixing models conceptualized the soil system as a combination of series and parallel blocks to represent different components (air, solid and water). Empirical models built the relationship between the thermal conductivity and water content by normalizing the effective thermal conductivity or using thermal conductivities of dry soils and saturated soils. Mathematic models were developed by calculating through the thermal conductivity of each component and corresponding volume fraction. Representative models for different classification and their expressions (Lehmann et al., 2003; Woodside and Messmer, 1961; Mickley, 1951; McGaw, 1969; Gens et al., 2009; Carson et al., 2005) were briefly introduced together with their own characteristics. In the end, some models were assessed by comparing with the experimental data for the prediction of different types of soil.

Besides the expressions and explanation for the above mentioned methods on the prediction of the rock-soil thermal conductivities, different methods also have their own applicability and limitations depending on diverse derivation procedures, which distinguishes themselves with one another theoretically. Various methods can be adopted for the corresponding rock-soil, but even for the same type of rock-soil, using different methods might lead to disparate results. It's important for us to find out the similarity and individuality, advantages and disadvantages of different methods for the application and properly choose the way suitable for the practical project depending on the case. Thus, this review gives 
detailed introduction to recent researches on both the theoretical methods and the experimental approaches to acquire the thermal conductivities of different types of rock-soil. The merit as well as limitations of different methods in their practical application is concluded for further use in geothermal energy.

\section{Theoretical methods}

The rock-soil can be thought as a mixture of three phases (as shown in Fig. 1). The thermal conductivity of different components varies across two orders of magnitude (Yun and Santamarina, 2008). The solid phase consists of different mineral and organic, whose conductivity depends on its component and generally speaking, its thermal conductivity $\lambda_{s}>2$ $\mathrm{W} /(\mathrm{m} \cdot \mathrm{K})$. The liquid phase refers to the water, whose conductivity $\lambda_{w}=0.56 \mathrm{~W} /(\mathrm{m} \cdot \mathrm{K})$ (at $\left.0{ }^{\circ} \mathrm{C}\right)$. Finally, the gas phase represents the air and its conductivity $\lambda_{a}=0.026 \mathrm{~W} /(\mathrm{m} \cdot \mathrm{K})$. As $\lambda_{w}$ is much higher than $\lambda_{a}$, the thermal conductivity of dry soil will be lower than that of saturated one. Abundant theoretical methods have been carried out in the past. All the theoretical models are divided into two types, i.e., the basic models and improved models.

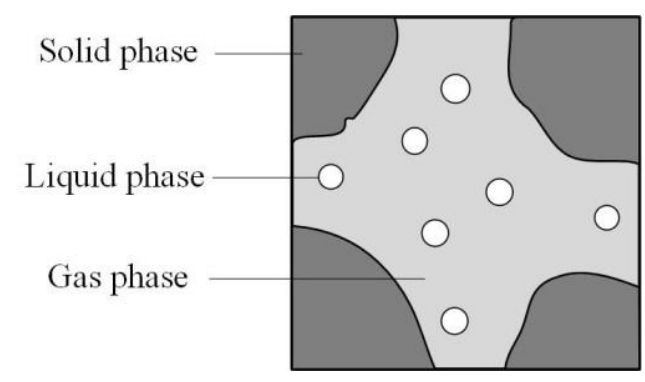

Fig. 1 Components of the soil.

\subsection{Basic models}

Basic models simplify the structure of the rock-soil. They either regard the components as homogeneous materials or simply define the arrangement of different phases so that the effective thermal conductivity can be calculated. The expressions of the thermal conductivities are derived based on either different average algorithms or the series and parallel theories. That is to say, basic models can be divided into simple homogeneous models as well as series and parallel models.

\subsubsection{Simple homogeneous models}


Simple homogeneous models assume that the rock-soil is homogeneous without considering the spatial distribution of different phases or the shape of solid particles. Different components contribute to the thermal conductivity only through their volume fractions, thus avoiding the trouble of studying the detailed structures of the rock-soil. Beck (1976) introduced some methods for the fluid-filled sedimentary rock's thermal conductivity calculation on the basis of an idealized model. The weighted geometric mean conductivity for the two-component system (saturated soil) was given by the following equation (Beck, 1976)

$$
\lambda=\lambda_{1}^{1-n} \lambda_{2}^{n}
$$

where $\lambda_{1}, \lambda_{2}$ are the thermal conductivity of the solid phase and liquid phase respectively, and $n$ is the porosity of the soil.

The Maxwell model (Maxwell, 1881) for the two-component material was also introduced, which had been successfully used for relatively small values of porosity $n<0.1$ and moderate conductivity ratio $r<10$. It could be expressed as (Maxwell, 1881),

$$
\lambda=\lambda_{s}\left[\frac{(2 r+1)-2 n(r-1)}{(2 r+1)+n(r-1)}\right]
$$

where $\lambda_{s}$ is the thermal conductivity of solid phase, $r$ is the conductivity ratio $\lambda_{s} / \lambda_{l}$ of the two-component system. By the use of appropriate correction factors obtained from data in other literatures, Maxwell model could be extended to much wider range of $r(<300)$ and $n(<$ $0.3)$.

Another method called weighted harmonic mean equation for the two-component system, assuming that the soil constituents had a series distribution that was perpendicular to the direction of heat flow, could be expressed as (Beck, 1976),

$$
\lambda=\frac{\lambda_{1} \lambda_{2}}{\phi_{1} \lambda_{2}+\phi_{2} \lambda_{1}}
$$

where $\lambda_{1}, \lambda_{2}$ are the thermal conductivities of the two components and $\phi_{1}, \phi_{2}$ are the corresponding volume fractions.

\subsubsection{Series and parallel models}

Series and parallel models define the configuration of different phases in the series or parallel connections, which make simplification on the structure of the rock-soil and at the 
same time, they delimit the upper and lower bounds of the thermal conductivity values.

Wiener's theory (Wiener, 1912) about the upper and lower bounds on the effective thermal conductivity has widely been used (as shown in Fig. 2). He indicated that the thermal conductivity of porous medium $\lambda$ including three phases (gas, liquid and solid) reached the lowest value when all the components were in series arrangement, while the highest in parallel arrangement. The lower value (series arrangement) could be expressed as follow (Wiener, 1912),

$$
\frac{1}{\lambda_{\text {lower }}}=\frac{\phi_{a}}{\lambda_{a}}+\frac{\phi_{l}}{\lambda_{l}}+\frac{\phi_{s}}{\lambda_{s}}
$$

where, $\phi_{a}, \phi_{l}, \phi_{s}$ are the volume fractions of the air phase, liquid phase and solid phase respectively. Similarly, the upper value (parallel arrangement) could be expressed as (Wiener, 1912),

$$
\lambda_{\text {upper }}=\phi_{a} \lambda_{a}+\phi_{l} \lambda_{l}+\phi_{s} \lambda_{s}
$$

For the saturated rock (as shown in Fig 3), the above two equations could be simplified to,

$$
\begin{aligned}
& \frac{1}{\lambda_{\text {lower }}}=\frac{\phi_{l}}{\lambda_{l}}+\frac{1-\phi_{l}}{\lambda_{s}} \\
& \lambda_{\text {upper }}=\phi_{l} \lambda_{l}+\left(1-\phi_{l}\right) \lambda_{s}
\end{aligned}
$$

Tighter bounds were later derived by Hashin and Shtrikman (H-S bounds) for the saturated rocks (Hashin and Shtrikman, 1962), compared to the series and parallel bounds (Hashin and Shtrikman, 1962),

$$
\lambda_{l}+\frac{3 \lambda_{l}\left(\lambda_{s}-\lambda_{l}\right)(1-n)}{3 \lambda_{l}+\left(\lambda_{s}-\lambda_{l}\right) n} \leq \lambda \leq \lambda_{s}+\frac{3 \lambda_{s}\left(\lambda_{l}-\lambda_{s}\right) n}{3 \lambda_{s}+\left(\lambda_{l}-\lambda_{s}\right)(1-n)}
$$

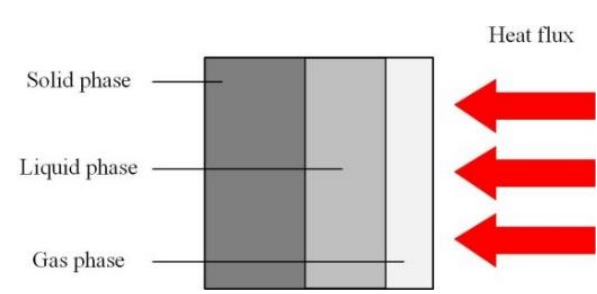

(a) series flow

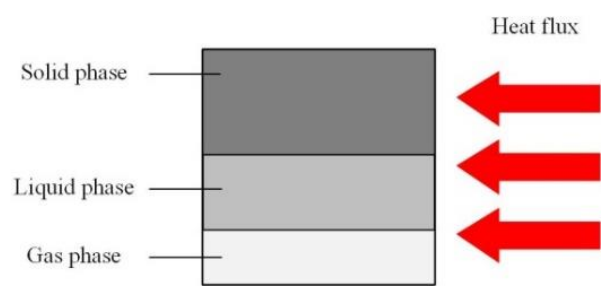

(b) parallel flow

Fig. 2 Series and parallel models for the effective thermal conductivity (a) series flow, (b) parallel flow. 


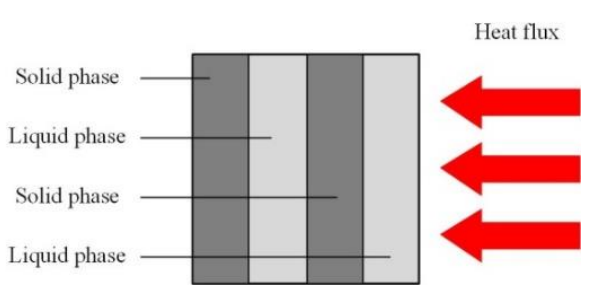

(a) series flow

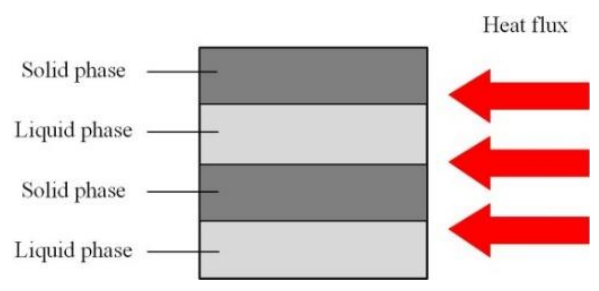

(b) parallel flow

Fig. 3 Effective thermal conductivity of a fluid-saturated rock, (a) series models, (b) parallel models.

From the above analysis, the simple homogeneous models, series and parallel models are conceptual models neglecting the real structure of the rock-soil. As shown in Fig. 4, taking the two-component system (saturated soils) as an example, the former method pays less attention to the detailed distribution of different components (shape of solid particles and water). The proportion of each component is reflected through its own volume fraction, i.e., the amount rather than the position or configuration. Therefore, the liquid phase is equivalently regarded as randomly distributed in the space. The only way to weigh the liquid phase to the effective thermal conductivity is its volume proportion associated with its thermal conductivity, which will be taken into account when giving the expression of the effective thermal conductivity. On the other hand, the series and parallel models consider more about the arrangement of different phases. By choosing different heat flow direction, the corresponding effective thermal conductivities can be obtained. This method mainly aims to provide the upper and lower limitations for the prediction values, based on which researchers can verify the reasonability of either measurement results or their own models to predict the thermal conductivity. It can also be combined with the experimental data to improve the prediction accuracy, which will be described in the next section. It is worth mentioning that both two models neglect the actual structure of the rock-soil more or less, therefore it might be difficult for them to provide accurate results on the thermal conductivity of the rock-soil theoretically. 


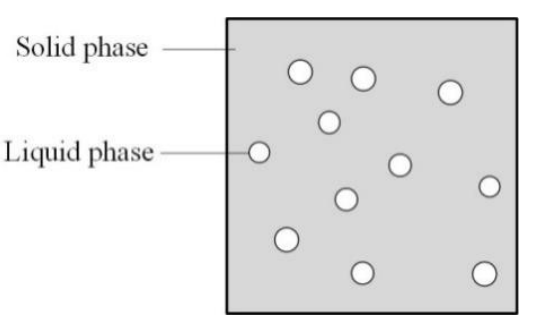

(a) simple homogeneous model

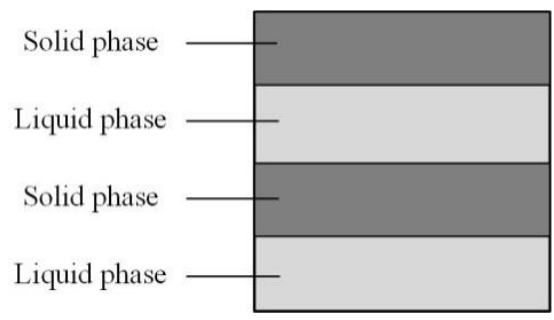

(b) series and parallel model

Fig. 4 Schematic diagram of (a) simple homogeneous model, (b) series and parallel model.

\subsection{Improved models}

In recent years, researchers contributed a great deal of attempt to more accurate thermal conductivity prediction. They either made improvement based on the above mentioned basic models, or combined the structures with the experimental data to obtain more accurate prediction for certain types of soils. Novel models with more complex structures were also presented to simulate the actual rock-soil structure. In general, the above mentioned improved models provide more accurate prediction than the basic models but had narrower scope in applications, as they were conducted according to specific types of rock-soil or under certain conditions

Tong et al. (2009) derived an effective thermal conductivity model in closed form for three-component mixture considering the combined effects of the solid mineral composition, temperature, liquid saturation degree, porosity and pressure, based on Wiener bounds and Hashin-Shtrikman bounds. They defined the individual thermal conductivities of the gas, liquid (water) and solid respectively, before the derivation of the effective thermal conductivity of two-component (soil-gas) and three-component mixture (soil-liquid-gas). The thermal conductivities of the gas and water were approximately calculated using the following two equations as functions of the density and temperature (for $200 K<T<500 K$ ) (Tong et al., 2009),

$$
\begin{aligned}
& \lambda_{a}=\left[4.55+0.072 T+(36.17-0.016 T) \rho_{a}+(47.4+0.121 T) \rho_{a}^{2}\right] \times 10^{-3} \\
& \lambda_{w}=\lambda^{*}\left[\bar{\lambda}_{0}(\bar{T})+\overline{\lambda_{1}}(\bar{\rho})+\overline{\lambda_{2}}(\bar{T}, \bar{\rho})\right]
\end{aligned}
$$

where $T, \rho_{a}$ are the temperature and density of the gas respectively, $\lambda^{*}=1.0 \mathrm{~W} /(\mathrm{m} \cdot \mathrm{K})$ is the reference thermal conductivity, $\bar{T}=T / T^{*}=0.001545 T$ is the dimensionless temperature, $\bar{\rho}$ 
$=\rho / \rho^{*}=0.0031476 \rho$ is the dimensionless density. The expressions of $\overline{\lambda_{0}}(\bar{T}), \overline{\lambda_{0}}(\bar{T}), \overline{\lambda_{0}}(\bar{T})$ have the form,

$$
\begin{array}{r}
\overline{\lambda_{0}}(\bar{T})=\sqrt{T}\left(0.0102811+0.0299621 \bar{T}+0.0156146 \bar{T}^{2}-0.00422464 \bar{T}^{3}\right) \\
\bar{\lambda}_{1}(\bar{\rho})=-0.39707+0.400302 \bar{\rho}+1.06 \exp \left[-0.171587(\bar{\rho}+2.39219)^{2}\right] \\
\bar{\lambda}_{2}(\bar{T}, \bar{\rho})=\left(0.0701309 \bar{T}^{-10}+0.011852\right) \bar{\rho}^{-1.8} \exp \left[0.642857\left(1-\bar{\rho}^{2.8}\right)\right] \\
+0.00169937 S \bar{\rho}^{W} \exp \left[\frac{W}{1+W}\left(1-\bar{\rho}^{1+W}\right)\right] \\
-1.02 \exp \left(-4.11717 \bar{T}^{1.5}-6.17937 \bar{\rho}^{-5}\right)
\end{array}
$$

where $W=2+0.0822994 \Delta \bar{T}^{-0.6}, S=\Delta \bar{T}^{-1}$ for $\bar{T} \geq 1$ and $S=10.0932 \Delta \bar{T}^{-0.6}$ for $\bar{T} \leq 1$. The thermal conductivity of the solid phase could be determined by considering the solid phase to be that of the soils or buffer materials (Tong et al., 2009),

$$
\lambda_{s}=\lambda_{q}^{\varsigma} \lambda_{o}^{1-\varsigma}
$$

where $\lambda_{q}$ and $\lambda_{o}$ are the thermal conductivities of the quartz and other minerals respectively depending on their types. $\varsigma$ is the quartz volume fraction. Based on Wiener and HashinShtrikman bounds, the effective thermal conductivity of the three-component mixture was finally obtained as (Tong et al., 2009),

$$
\begin{aligned}
\lambda=\eta_{1}(1-n) \lambda_{s}+\left(1-\eta_{2}\right)\left[1-\eta_{1}(1-n)\right]^{2} \times\left[\frac{(1-n)\left(1-\eta_{1}\right)}{\lambda_{s}}+\frac{n S_{r}}{\lambda_{w}}+\frac{n\left(1-S_{r}\right)}{\lambda_{g}}\right]^{-1} \\
+ \\
+\eta_{2}\left[(1-n)\left(1-\eta_{1}\right) \lambda_{s}+n S_{r} \lambda_{w}+n\left(1-S_{r}\right) \lambda_{g}\right]
\end{aligned}
$$

where $\eta_{1}, \eta_{2}$ are the coefficients being functions of the pore structure, which can be determined through experiment. $S_{r}$ is the degree of saturation. This general model was then verified by comparing with the experimental data of a kind of bentonite, a buffer material from Wyoming, USA. The model was shown to satisfy Wiener bounds and Hashin-Shtrikman bounds very well (for $0.04 \leq n \leq 0.97$, and $0 \leq S_{r} \leq 1$ ) and at the same time to make accurate prediction.

Johansen (1977) proposed a concept called the normalized thermal conductivity (Johansen, 1977), 


$$
\lambda_{r}=\frac{\lambda-\lambda_{d r y}}{\lambda_{s a t}-\lambda_{d r y}}
$$

where $\lambda_{d r y}$ and $\lambda_{\text {sat }}$ are the thermal conductivities of the dry soil and the saturated soil respectively. It could be seen that for the dry soil, $\lambda_{r}=0$ and for the saturated soil, $\lambda_{r}=1$. For the unsaturated soil, $\lambda_{r}$ was determined by the degree of saturation $S_{r}$. Based on this, Côté and Konrad (2005) presented a generalized thermal conductivity model, which took into account the frozen and unfrozen based-course and subbase materials (Côté and Konrad, 2005),

$$
\lambda_{r}=\frac{\kappa S_{r}}{1+(\kappa-1) S_{r}}
$$

where $\kappa$ is an empirical parameter, describing the thermal behavior of different types of soils in both the unfrozen and frozen states. The parameters $\lambda_{d r y}$ and $\lambda_{\text {sat }}$ were calculated using the following equations respectively (Côté and Konrad, 2005),

$$
\begin{aligned}
& \lambda_{\text {sat }}=\lambda_{s}^{1-n} \lambda_{l}^{n} \\
& \lambda_{s}=\prod_{j} \lambda_{j}^{x_{j}}
\end{aligned}
$$

where $\lambda_{j}$ is the thermal conductivity of the rock-forming mineral $j, x$ is the volumetric proportion of the component $j$. After comparing the calculating results with nearly 220 experimental data obtained from other literatures (Smith, 1942; Smith and Byers, 1939; Slusarchuk and Watson, 1975; Kersten and Miles, 1949; Côté and Konrad, 2005) on four types of soils (as shown in Table 1), the accuracy of the model was verified covering the entire range of the degree of saturation. What's more, the paper presented some values for the thermal conductivities of different kinds of solid particles, which were useful data to other researches for reference.

\section{Table 1}

Four types of soils used in Côté's work (Côté and Konrad, 2005).

\begin{tabular}{ccc}
\hline Soil type & Density $/ \mathrm{kg} \cdot \mathrm{m}^{-3}$ & Water content $/ \%$ \\
\hline Crushed granite (well-graded coarse sand) & 1926 & 3.9 \\
Lowell sand (natural medium sand) & 1691 & 11.0 \\
Healy clay (natural soil) & 1293 & 34.8 \\
Fairbanks peat (organic fibrous soil) & 332 & 185.0 \\
\hline
\end{tabular}


Gyu-Hyun et al. (2016) presented an empirical model to predict the thermal conductivity using the method of artificial neural network (ANN). The expression of the model was (Go et al., 2016),

$$
\lambda_{\mathrm{eff}}=\lambda_{\text {sat }}+\left(\lambda_{d r y}-\lambda_{\text {sat }}\right) \cdot \frac{1}{1+p \cdot \exp \left(q \cdot S_{r}\right)}
$$

where $\lambda_{d r y}$ and $\lambda_{\text {sat }}$ were obtained through Lee's (2010) work. The curve fitting coefficients $p$ and $q$ should have been determined by the measurement data, but in order to make the model more practical, they were determined through ANN, which yielded a certain output with computing a large number of data representing the features and the information of the soil without experiments (see Fig. 5). The input layer provided the information (including the particle thermal conductivity, porosity, dry thermal conductivity, fully saturated thermal conductivity, etc.) to the network. In the hidden layer, each node multiplied every input by its interconnection weight. After summing the product, they passed the sum result through a transfer function to the output layer to represent the nodal output. Each node was an independent computational unit, which worked depending on the following formula (Go et al., 2016),

$$
y_{j}=f\left(\Sigma w_{i j} x_{i}+\theta_{j}\right)
$$

where $y_{j}$ is the transformed output by the $j$ th hidden neuron, $x_{i}$ is the input of the $i$ th neuron in the previous layer, $w_{i j}$ is the weight of the connection joining the $j$ th neuron in a layer with the $i$ th neuron in the previous layer, $\theta_{j}$ is the bias at the $j$ th neuron and $f$ is the transfer function controlling the output of a neuron. The model was then verified by the experimental data of the unsaturated weathered granite soils measured by a typical needle probe device. The model was shown to accurately predict the effective thermal conductivity of the soil at the test conditions $(n=0.26,0.32,0.36,0.53)$

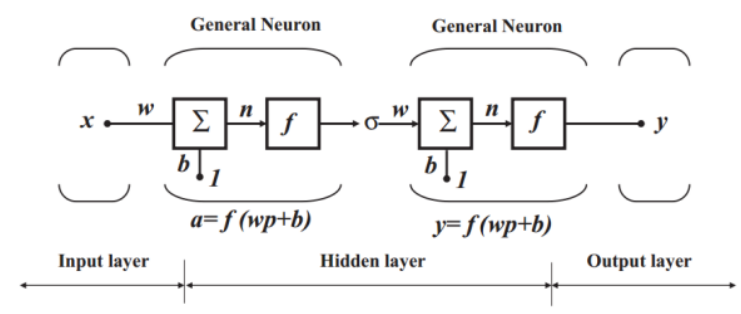

Fig. 5 Feed forward network of ANN model (Go et al., 2016). 
Lu et al. (2007) introduced an improved model estimating the soil bulk density, sand fraction and water content, to describe the relationship between the water content and the thermal conductivity. Based on Johansen's work on the normalized thermal conductivity and Kersten's work (Kersten and Miles, 1949) on the normalized water content, as well as the geometric mean equation, they proposed the following equations about the normalized thermal conductivity $K_{e}$ to $S_{r}$ and the relationship between dry soil thermal conductivity $\lambda_{d r y}$ and porosity $n$ (Lu et al., 2007),

$$
\begin{aligned}
& K_{e}=\exp \left\{\varphi\left[1-S_{r}^{(\alpha-1.33)}\right]\right\} \\
& \lambda_{d r y}=-a n+b
\end{aligned}
$$

Where $\varphi$ is a soil texture dependent parameter, 1.33 is a shape parameter, $a$ and $b$ are the empirical parameters. The determination of them could be realized through fitting the measured data. Other parameters that need to be calculated were then obtained using the methods described by Johansen (1977) with $\lambda_{d r y}$ and $S_{r}$ obtained above. The results were validated with twelve soils (ten from China and two from Iowa, US.), whose thermal conductivities were measured by a thermo-time domain reflectometry probe (Johansen, 1977; Kersten and Miles, 1949; Farouki, 1982). After comparing with Johansen's model and the measured data, Konrad's (Kersten and Miles, 1949) model and the measured data, the new model was able to closely describe $\lambda$ across the entire water content range for the soils of various textures. The relative error with the measured value was also lower compared to that of the other two models, except for the relative high sensitivity to the quartz fraction for the sand at water contents $>0.2 \mathrm{~m}^{3} \mathrm{~m}^{-3}$.

Haigh (2012) proposed an analytical cylindrical model with axisymmetric structure based on the unidirectional heat flow through a three-component soil element (see Fig. 6). The model consisted of three parts (solid particle, water and air) and its length and width are $R(1+$ $\xi)$ and $R$ respectively. Different values of $\xi$ corresponded to different voids ratios and $\beta$ could represent the degree of saturation (water content). Water was assumed to be held by the surface tension in the voids separated from the air and its curvature of the menisci was ignored. The total volume of the unit would be controlled by $\xi$ and $\beta$ together. Through calculating the corresponding volume to get the thermal resistance of the cylindrical unit cell 
and integrating from $\beta R$ to $R$, the overall thermal conductivity of the soil medium could be expressed as (Haigh, 2012),

$$
\begin{array}{r}
\frac{\lambda}{\lambda_{s}}=2(1+\xi)^{2}\left\{\frac{\alpha_{w}}{\left(1-\alpha_{w}\right)^{2}} \ln \left[\frac{(1+\xi)+\left(\alpha_{w}-1\right) x}{\xi+\alpha_{w}}\right]+\frac{\alpha_{a}}{\left(1-\alpha_{a}\right)^{2}} \ln \left[\frac{1+\xi}{(1+\xi)+\left(\alpha_{a}-1\right) x}\right]\right\} \\
+\frac{2(1+\xi)}{\left(1-\alpha_{w}\right)\left(1-\alpha_{a}\right)}\left[\left(\alpha_{w}-\alpha_{a}\right) x-\left(1-\alpha_{a}\right) \alpha_{w}\right]
\end{array}
$$

where $x=\sqrt{\left(1-\beta^{2}\right)}, \alpha_{w}$ and $\alpha_{a}$ are the thermal conductivities, normalized by that of the soil solids, of the water and the air respectively. They could be obtained from,

$$
\alpha=\frac{\lambda_{l}}{\lambda_{s}}
$$

The author then compared the prediction results with the nine models proposed by other researchers (Johansen, 1977; Côté and Konrad, 2005; Lu et al., 2007; Chen, 2008; Donazzi et al., 2010; Gangadhara and Singh, 1999) for porosity $n=0.472$ before taking into consideration a larger data base available in the references (Chen, 2008; Donazzi et al., 2010; Gangadhara and Singh, 1999; Moench and Evans, 1970; McInnes, 1981; Ewen and Thomas, 1987), as shown in Fig. 7. All the ten prediction methods provided good estimation of the trend of the dataset. After the linear regression analysis, the method proposed in the Haigh's work was proved to have lower errors than other nine models during its prediction process for the highest $R^{2}$ value and the lowest standard error.

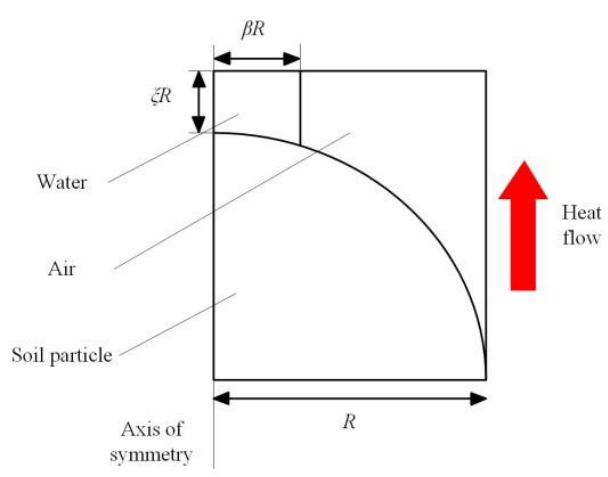

Fig. 6 Geometry of axisymmetric contact model (half). 


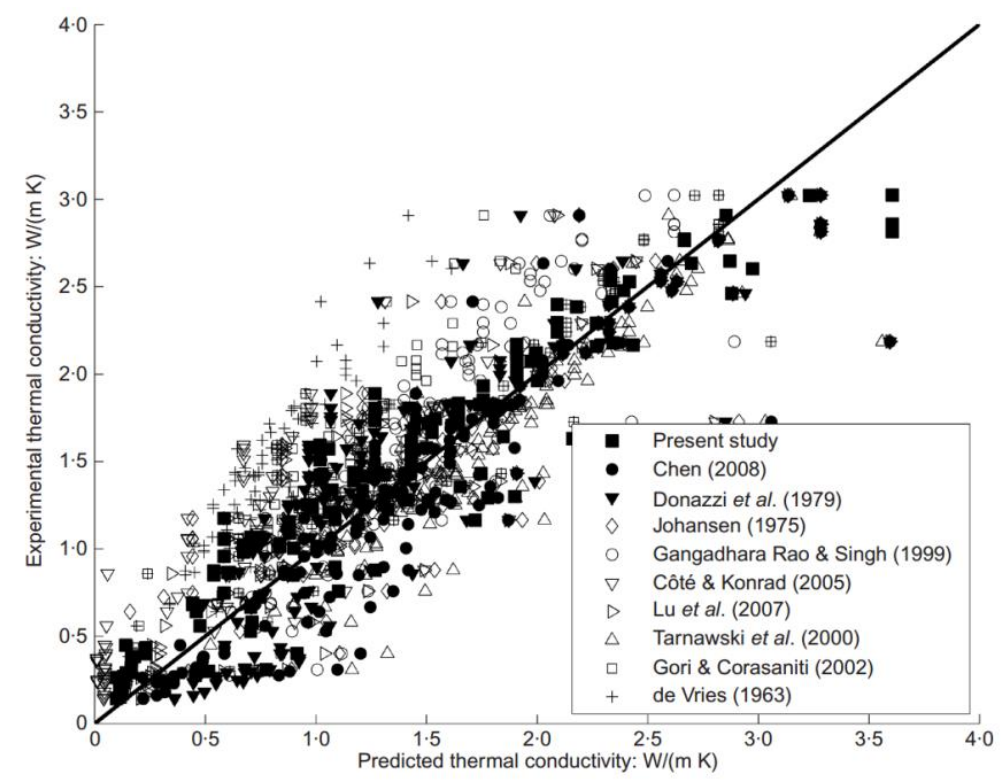

Fig. 7 Comparison of ten prediction methods on large database (Haigh, 2012)

Table 2

Linear regression fits comparing predicted and measured thermal conductivities (Haigh, 2012)

\begin{tabular}{ccccc}
\hline & Gradient & $\mathrm{R}^{2}$ & $\begin{array}{c}\text { Standard error/ } \\
\mathrm{W} \cdot \mathrm{m}^{-1} \mathrm{~K}^{-1}\end{array}$ & $\begin{array}{c}\text { Number of data } \\
\text { points }\end{array}$ \\
\hline Haigh, 2012 & 1.00 & 0.86 & 0.24 & 151 \\
Chen, 2008 & 0.92 & 0.85 & 0.29 & 155 \\
Lu et al., 2007 & 0.98 & 0.78 & 0.32 & 150 \\
Côté and Konrad, 2005 & 1.00 & 0.70 & 0.32 & 155 \\
Gori and Corasaniti, 2002 & 1.17 & 0.79 & 0.31 & 155 \\
Tarnawski et al., 2000 & 1.28 & 0.54 & 0.38 & 155 \\
Gangadhara Rao and Singh, & 1.13 & 0.77 & 0.31 & 131 \\
1999 & & & & 155 \\
Donazzi et al., 1979 & 1.00 & 0.73 & 0.38 & 130 \\
Johansen, 1977 & 0.96 & 0.65 & 0.32 & 125 \\
de Vries, 1963 & 0.89 & 0.78 & 0.29 & \\
\hline
\end{tabular}

Gori and Corasaniti (2013) evaluated the effective thermal conductivity of the three-component rock-soil using a new model without any empirical constants. As shown in Fig. 8, the elementary cell was a cube (with the side equal to $2 l$ ) with a larger spherical shell (of radius $R_{1}$ larger than $l$ ) inside. The sphere of radius $R_{1}$ without six sections (because its external radius $R_{2}$ is greater than the cube half side $l$ ) represented the solid grain. The water was set around the solid part and the air was assumed to fill the rest space (between water 
sphere and the cube, as shown in Fig. 9a). The porosity and saturation degree could be obtained accordingly. Following assumptions were adopted, (1) the heat transfer was steady state conduction and the parallel heat flux was along $z$ direction (see Fig. 9b and Fig. 9c); (2) the isotherms were assumed parallel to the $x-y$ plane, thus the temperature variation was one-dimensional ( $z$ direction). Under the above assumptions, the effective thermal conductivity could be solved as (Gori and Corasaniti, 2013),

$\lambda=\frac{q_{1}+q_{2}+q_{3}+q_{4}+q_{5}+q_{6}}{2 l \Delta T}$

where $\Delta T$ is the temperature surface between the upper and lower surfaces. Detailed integrating results of heat flux were also demonstrated.

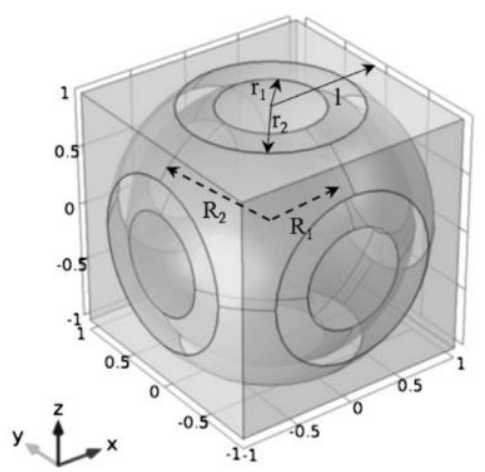

Fig. 8 Elementary cell of the model (Gori and Corasaniti, 2013).

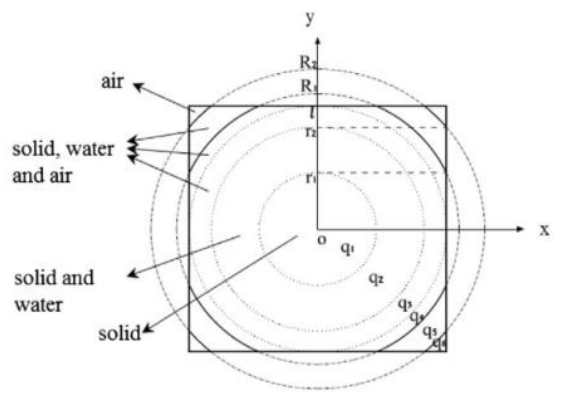

(a) view from above

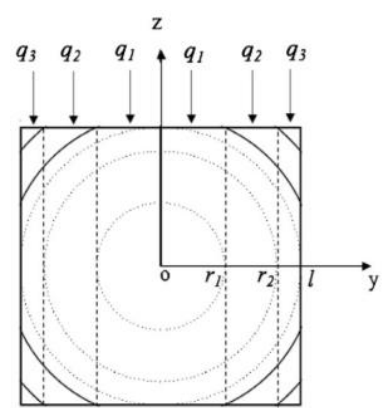

(b) side view

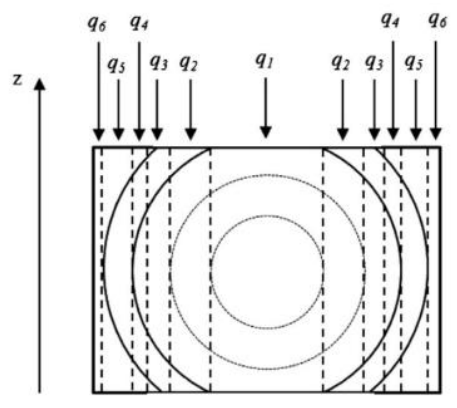

(c) diagonal section

Fig. 9 Different views of the model (a) view from above, (b) side view, (c) diagonal section (Gori and Corasaniti, 2013).

The model was then verified by the experimental data for the frozen and the unfrozen soils (Wang and Pan, 2008; Farouki, 1982; Campbell et al., 1994) and the results were 
summarized in Table 3. The relative errors were shown to be around $10 \%$, which indicated that the predicted values of the model were in good agreement with the experimental data.

Table 3

Experimental results used in Gori and Corasaniti's work (Gori and Corasaniti, 2013).

\begin{tabular}{|c|c|c|c|c|}
\hline Literature & Soil type & Porosity & $\begin{array}{l}\text { Thermal conductivity } \\
\text { of solid part } / \mathrm{W} \cdot \mathrm{m}^{-1} \mathrm{~K}^{-1}\end{array}$ & $\begin{array}{l}\text { Relative } \\
\text { error }\end{array}$ \\
\hline $\begin{array}{c}\text { Campbell et al., } \\
1994\end{array}$ & $\begin{array}{l}\text { Royal, unfrozen } \\
\text { soil }\end{array}$ & 0.400 & 2.570 & $\pm 8 \%$ \\
\hline Johansen, 1977 & Unfrozen sand & 0.500 & 2.850 & $\pm 11 \%$ \\
\hline Johansen, 1977 & Frozen sand & 0.500 & 2.850 & $\pm 12 \%$ \\
\hline Farouki, 1982 & Frozen clay & 0.320 & I & $\pm 2 \%$ \\
\hline Farouki, 1982 & Frozen silty loams & 0.439 & 2.043 & l \\
\hline
\end{tabular}

The above mentioned models are intended to increase the accuracy of the thermal conductivity prediction and they can be roughly divided into the types as classified below,

(1) They calculate the thermal conductivities of certain phases based on the basic models, combined with other parts and at the same time considering the influence of the temperature, pressure and so on (Tong et al., 2009; Johansen, 1977).

(2) They put forward equations containing the undetermined parameters with the simple form or referring to the upper and lower bounds. Make use of experimental data to determine the parameters in the equations for the purpose of improving the accuracy for the certain rock-soil (Côté and Konrad, 2005; Go et al., 2016; Lu et al., 2007).

(3) They present the novel structure models related to the actual rock-soil structure in order to simulate the heat flow across the unit (usually assume one dimension heat flow) (Haigh, 2012; Gori and Corasaniti, 2013).

All of the above types aim at improving the prediction accuracy through their own methods. On one hand, they tried to find the relationship between the actual structure of the soils and their models attempt to build "bridge" for similarity without making the calculation process too complicated. For the work of Haigh (2012) and Gori (Gori and Corasaniti, 2013), they developed the new models different but relatively close to the real structure of the soil compared to the basic ones. The structure parameters ( $\xi$ and $\beta$ for Haigh's model, $R_{1}, R_{2}, l$ for 
Gori's model) act as the "bridge" between the models and the real structure by controlling the proportions of different phases (as shown in Fig. 5 and Fig. 6, once these parameters change, the volume of different phases change accordingly). Therefore, the water content, solid particle sizes and other parameters can be represented by several simple parameters, which greatly increase the unity of the system. On the other hand, some authors presented their equations with the help of the experimental results to determine the undetermined parameters (like the work of Lu et al. (2007), the shape parameter of 1.33, the coefficients $a$ and $b$ were determined through experiment). They paid attention to the type of the soils and directly investigated their thermal conductivities without concerning other factors. The results are able to predict the thermal conductivity of the target soils accurately but might not be suitable for other rock-soil types.

\subsection{Summary of theoretical models}

As stated above, all of the mentioned theoretical models can be divided into different types. At the same time, they also have their own application range of the porosity, saturation degree, advantages and deficiencies. Different models also aim at different types of rock-soil. All of the applicability information has been summarized in Table 4 for reference and consulting.

In general, the theoretical methods can provide rough prediction results of the thermal conductivities. But the calculating expressions can be used on the rock-soil for a wide range of properties and saturation degree in different places. Once the necessary parameters (like the thermal conductivities of different types of rocks) are obtained, the effective thermal conductivities in different areas can be predicted, which will be beneficial to the estimation of the operating performance of ground buried heat exchangers. 


\section{Table 4}

Summary of the theoretical models.

\begin{tabular}{|c|c|c|c|c|c|c|c|}
\hline \multirow[b]{2}{*}{ Authors } & \multicolumn{2}{|c|}{ Scope of application } & \multirow[b]{2}{*}{ Phases } & \multirow{2}{*}{$\begin{array}{l}\text { Final expression of } \\
\text { thermal } \\
\text { conductivity models }\end{array}$} & \multirow[b]{2}{*}{ Comments } & \multirow[b]{2}{*}{ Advantages } & \multirow[b]{2}{*}{ Disadvantages } \\
\hline & Porosity & $\begin{array}{l}\text { Degree of } \\
\text { saturation }\end{array}$ & & & & & \\
\hline $\begin{array}{l}\text { Côté and } \\
\text { Konrad, } \\
2005\end{array}$ & $0 \sim 1$ & $0 \sim 1$ & $\begin{array}{l}\text { Saturated and } \\
\text { unsaturated, } \\
\text { frozen and } \\
\text { unfrozen }\end{array}$ & (18) & $\begin{array}{c}\text { Based on Johansen's work of } \\
\text { normalized thermal } \\
\text { conductivity, verified by four } \\
\text { types of soils }\end{array}$ & $\begin{array}{l}\text { Covered all range of porosity and } \\
\text { saturation degree, frozen and unfrozen } \\
\text { soil, accurate prediction }\end{array}$ & $\begin{array}{c}\lambda_{d r y} \text { and } \lambda_{\text {sat }}, S_{r} \text { and } \kappa \text { should be } \\
\text { gotten separately, relatively } \\
\text { complicated calculation } \\
\text { process }\end{array}$ \\
\hline $\begin{array}{l}\text { Lu et al., } \\
2007\end{array}$ & $0 \sim 1$ & $0 \sim 1$ & $\begin{array}{l}\text { Saturated and } \\
\text { unsaturated }\end{array}$ & $(23)$ & $\begin{array}{l}\text { Based on Johansen's work of } \\
\text { normalized thermal } \\
\text { conductivity and normalized } \\
\text { water content, verified by soils } \\
\text { from China and Iowa (different } \\
\text { kinds of sands and loams) }\end{array}$ & $\begin{array}{l}\text { Accurate prediction, all range of saturation } \\
\text { degree, new way to determine } \lambda_{d r y}\end{array}$ & $\begin{array}{l}\text { Lots of parameters need to be } \\
\quad \text { obtained or calculated } \\
\text { beforehand }\left(a, b, \lambda_{d r y}, \lambda_{\text {sat }} \text { and } S_{r}\right)\end{array}$ \\
\hline $\begin{array}{l}\text { Tong et } \\
\text { al., } 2009\end{array}$ & $\begin{array}{c}0.04 \sim \\
0.97\end{array}$ & $0 \sim 1$ & Three phases & (16) & $\begin{array}{l}\text { Based on Wiener and Hashin-- } \\
\text { Shtrikman bounds, verified by } \\
\text { bentonite, a buffer material } \\
\text { from Wyoming, USA }\end{array}$ & Accurate prediction & $\begin{array}{l}\text { Coefficients } \eta_{1}, \eta_{2} \text { should be } \\
\text { obtained through experimental } \\
\text { approaches for different } \\
\text { porosities and saturation }\end{array}$ \\
\hline $\begin{array}{l}\text { Haigh, } \\
2012\end{array}$ & $0 \sim 1$ & $0 \sim 1$ & $\begin{array}{l}\text { Three phases } \\
\text { sand }\end{array}$ & $(25)$ & $\begin{array}{l}\text { Suppose heat flow from a single } \\
\text { direction, for sands, compared } \\
\text { with other } 9 \text { models and } 155 \\
\text { data points from } 6 \text { references }\end{array}$ & $\begin{array}{l}\text { Satisfy the experimental data very well, } \\
\text { the lowest value compared to other nine } \\
\text { model }\end{array}$ & $\begin{array}{l}\text { Complex calculating process, } \\
\text { have not been verified for other } \\
\text { types of rocks }\end{array}$ \\
\hline $\begin{array}{l}\text { Gori and } \\
\text { Corasaniti, } \\
2013\end{array}$ & $\begin{array}{l}0.0349 \\
\sim \\
0.4734\end{array}$ & $0 \sim 1$ & $\begin{array}{l}\text { Three phases, } \\
\text { unfrozen and } \\
\text { frozen soils }\end{array}$ & $(27)$ & $\begin{array}{l}\text { Soil is made of a } \\
\text { quasi-spherical solid grain, and } \\
\text { is surrounded by two phases }\end{array}$ & Without empirical constants & $\begin{array}{l}\text { Cannot cover the entire } \\
\text { porosity range, relatively } \\
\text { complex form of } q_{1} \sim q_{6}\end{array}$ \\
\hline $\begin{array}{l}\text { Go et al., } \\
2016\end{array}$ & $0 \sim 1$ & $0 \sim 1$ & $\begin{array}{l}\text { Unsaturated } \\
\text { soil }\end{array}$ & $(21)$ & $\begin{array}{l}\text { Use ANN method, verified by } \\
\text { unsaturated weathered granite } \\
\text { soils }\end{array}$ & $\begin{array}{l}\text { Accurate prediction, coefficient } p, q \text { can be } \\
\text { obtained before experiment }\end{array}$ & $\begin{array}{c}\lambda_{d r y} \text { and } \lambda_{\text {sat }} \text { should be obtained } \\
\text { from the experiment or other } \\
\text { work }\end{array}$ \\
\hline
\end{tabular}




\section{Experimental approaches}

Besides theoretical methods, the experimental approaches have also been widely used for direct measuring the average thermal conductivity value along the borehole heat exchanger (Gehlin and Hellström, 2003). As one of the most frequently used method, the Thermal Response Test (TRT) was first presented by Mogensen (1983) using line source theory (see Fig. 10). The solution of the line source model for the heat exchanger could be expressed as follow (Morgensen, 1983),

$$
T(t)=T_{u g}+\frac{Q}{4 \pi \lambda H} E l\left(\frac{r_{b}^{2}}{4 a t}\right)+\frac{Q}{H} \cdot R_{b}
$$

where $T(t)$ is the circulation fluid temperature, $T_{u g}$ is the initial undisturbed ground temperature, $Q$ is the injected heat power rate, $H$ is the effective bore depth, $r_{b}$ is the borehole radius, $a$ is the thermal diffusivity of the ground, $t$ is the running time and $R_{b}$ is the thermal resistance between the fluid and the borehole wall. Besides,

$$
E l(x)=\int_{x}^{\infty} \frac{e^{-u}}{u} d u
$$

when regarding the thermal process within the borehole as nearly steady-state condition,

$$
E l(x) \approx \ln \frac{1}{x}-\gamma \text { for } \frac{a t}{r_{b}^{2}} \geq 5
$$

where $\gamma$ is Euler's constant and $\gamma \approx 0.5772$. Then Eq. (28) can be further simplified as,

$$
T(t)=T_{u g}+\frac{Q}{4 \pi \lambda H}\left[\ln \left(\frac{4 a}{r_{b}^{2}} \cdot t\right)-\gamma\right]+\frac{Q}{H} \cdot R_{b}
$$

A certain amount of heat flux was injected into the buried heat exchanger over a period time of several days. By measuring the inlet and outlet fluid temperature, the average circulation fluid temperature could be obtained to represent $T(t)$. Once the curve of $T(t)-Q$ was acquired, the effective thermal conductivity could be known according to the its slope. 


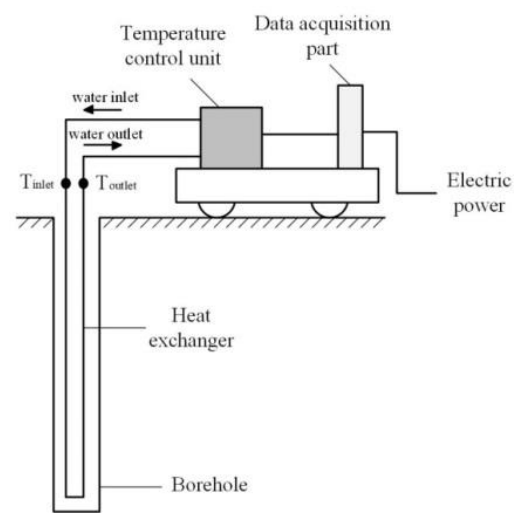

Fig. 10 Schematic of the thermal response test system.

Yu et al (2016) carried out the TRT to analyze the performance of the ground heat exchanger based on the cylindrical source model (Deerman, 1991),

$T_{u g}-T(t)=\frac{Q}{\lambda H} G\left(F_{0}, p\right)$

where $F_{0}=\alpha t / r_{b}^{2}$ and $p=r / r_{b}$ are the dimensionless time and dimensionless length respectively. When $p=1$, the expression of $G$ function is,

$G\left(F_{0}, 1\right)=10^{\left(-0.89129+0.36081 \lg F_{0}-0.05508 \lg ^{2} F_{0}+3.596 \times 10^{-3} \times \lg ^{3} F_{0}\right)}$

To satisfy the feasibility of the cylindrical source model, the surrounding rock-soil was assumed to have constant thermal properties with infinite cylinder borehole. Meanwhile, the ground was divided into sub-layers with the thickness of $5 \mathrm{~m}$ to allow for the vertical variation in the rock-soil thermal properties. After acquiring the thermal conductivity distribution in the ground based on the vertical temperatures, the results were then compared with the test results from the two boreholes $(300 \mathrm{~mm}$ diameter, $92.5 \mathrm{~m}$ and $92.8 \mathrm{~m}$ depth respectively) with high-density polyethylene double U-tubes. Both the constant temperature method and the constant heat-flux method were adopted and the average relative errors of the thermal conductivity calculation were of $5.4 \%$ and $14.8 \%$ respectively. The results showed that the estimated thermal conductivities are well consistent with the actual values.

Han et al (2018) investigated the influence of two different identification models on the accuracy of the TRT. They established a 3-D numerical model to simulate the 
TRT of a $63 \mathrm{~m}$ deep borehole with a U-tube inside it, whose external diameter was 32 $\mathrm{mm}$. A test bench consisted of the sand box $(2.5 \mathrm{~m} \times 2.0 \mathrm{~m} \times 1.0 \mathrm{~m})$, copper $\mathrm{U}-$ tube heat exchanger (DN 20), and other necessary equipment was then built to verify the accuracy of the model, before the line source model and the cylindrical source model were adopted to determine the soil thermo-physical parameters for the numerical simulation. By comparing the experimental results with the simulation ones, the effects of adopting the two identification models on the accuracy of predicting the soil thermal parameters were analyzed in detail. The results showed that the relative errors become lower with the extension of time and with the increase of the soil thermal conductivity. The minimum relative error point was called the optimal test time (when the relative error is zero), which gradually advanced with the increase of the soil thermal conductivity. Thus, it would be possible to choose the proper operating time for achieving higher accuracy.

Rohner et al. (2005) developed a small, light, wireless borehole probe, which consisted of pressure and temperature sensors (with a temperature resolution of $\pm 0.003{ }^{\circ} \mathrm{C}$ ) and a mini-data logger/programmed microprocessor packed in a closed metal tube, to rapidly measure the ground thermal conductivity for the borehole heat exchanger located in Im Wiesental near Zurich, Switzerland. Temperature and pressure sensors in the metal tube transmitted electrical signal through the instrument amplifier and $\mathrm{A} / \mathrm{D}$ converter to the microprocessor, which undertook the mission of data processing. The field measurement of the temperature-depth profiles by the probe in the selected borehole for a depth of $300 \mathrm{~m}$ was presented. Gradient was calculated with the original measurement spacing of $\Delta z=1.1 \mathrm{~m}$ and smoothed over $\Delta z=13 \mathrm{~m}$. The geologic column showed that gravel, sandstone and clay were the three main components in this area. The temperature gradient of soil was $22.2{ }^{\circ} \mathrm{C} / \mathrm{km}$, $30.2{ }^{\circ} \mathrm{C} / \mathrm{km}$ and $41.4{ }^{\circ} \mathrm{C} / \mathrm{km}$ for the depth range of around $10 \sim 40 \mathrm{~m}, 40 \sim 100 \mathrm{~m}$ and $100 \sim$ $300 \mathrm{~m}$ respectively. Laboratory measurement of the thermal conductivities on the cuttings from the same boreholes was also presented. The thermal conductivities of the soil varied from $2 \mathrm{~W} /(\mathrm{m} \cdot \mathrm{K})$ to $5 \mathrm{~W} /(\mathrm{m} \cdot \mathrm{K})$ at the first $50 \mathrm{~m}$ and then stabilized at around $2 \mathrm{~W} /(\mathrm{m} \cdot \mathrm{K})$ with the increasing soil depth. Good agreement had been reached after comparing the laboratory 
results with the thermal conductivities derived from the measured temperature gradient and the local heat flow, which validated the reliability of the method of the thermal conductivity measurement.

Alishaev et al. (2012) measured the effective thermal conductivity of dry and fluid (gas-, oil-, and water)-saturated rocks as listed in Table 5, with various porosities over a temperature range from $273 \mathrm{~K}$ to $523 \mathrm{~K}$ at the atmospheric pressure using a steady-state guarded parallel-plate apparatus, which had an operational temperature range from $270 \mathrm{~K}$ to $600 \mathrm{~K}$ and hydrostatic pressures up to $1000 \mathrm{MPa}$. Through simultaneously measuring the steady-state heat flux and temperature gradient (provided by temperature regulator) in the sample between the heating and cooling plates, the thermal conductivity of the rock-soil could be obtained. The temperature of the samples was incremented by $50 \mathrm{~K}$ for each test and the results were then compared with the measured and predicted values of the effective thermal conductivities of water-, gas-, and oil-saturated soil obtained from existing works (Zimmerman, 1989; Hsu et al., 1994; Hsu et al., 1995; Kunii and Smith, 1960; Hadley, 1986; Zehner and Schlunder, 1970; Keller et al., 1999; Buntebarth and Rueff, 1987; Tikhomirov, 1968; Sass et al., 1971; Funnell, 1996; Anand, 1971; Anand et al., 1973; Asaad, 1955; Sekiguchi, 1984; Rzhevsky and Novik, 1971; Fricke and Hugo, 1924). The results showed that for the same rock, the effective thermal conductivity of the water saturated sample was higher than that of the oil saturated one, while the air saturated rock was the lowest. The temperature change of the sandstone, limestone, amphibolite and granulate were nearly linear and decreased with the increase of the temperature, while for the siltstone, pyroxene-granulate, and andesite monotonically increased with the temperature of different rates. For dolomite ETC was almost independent of the temperature. Besides, a new simplified model for the prediction of the effective thermal conductivity of saturated rocks was proposed (suitable for $\left.\lambda_{l}<<\lambda_{s}\right)$. The model took into account the structure and the porosity, which is shown as below (Alishaev et al., 2012),

$$
\lambda=\left[1-\sqrt[3]{\left(n / n_{0}\right)^{2}}\right] \lambda_{s}+\sqrt{\lambda_{s} \lambda_{l}\left(n / n_{0}\right)}
$$

where $n_{0}$ is the maximum possible value of the porosity, $0 \leq n \leq n_{0}$. At $n=n_{0}$ (i.e., saturated situation), the above equation can be further simplified as, 


$$
\lambda=\sqrt{\lambda_{s} \lambda_{f}}
$$

\section{Table 5}

Materials description for Alishaev's work (Alishaev et al., 2012).

\begin{tabular}{|c|c|c|c|c|c|}
\hline Rock Type & Sample sites & $\begin{array}{c}\text { Depth/ } \\
\text { m }\end{array}$ & Porosity & $\begin{array}{l}\text { Density/ } \\
\mathrm{kg} \cdot \mathrm{m}^{-3}\end{array}$ & Comment \\
\hline Sandstone-1 & $\begin{array}{c}\text { Aktash, } \\
\text { Dagestan, Russia }\end{array}$ & 2997 & $5 \%$ & 2180 & $\begin{array}{l}\text { Weakly cemented, gray } \\
\text { color, moderate grained, and } \\
\text { slightly aerated }\end{array}$ \\
\hline Sandstone-2 & $\begin{array}{c}\text { Buinaks, } \\
\text { Dagestan, Russia }\end{array}$ & l & $16.2 \%$ & 2700 & l \\
\hline Sandstone-3 & $\begin{array}{c}\text { Solonchak, } \\
\text { Dagestan, Russia }\end{array}$ & 3941 & $13 \%$ & 2180 & $\begin{array}{l}\text { Weakly cemented, weakly } \\
\text { carbonated, gray color, } \\
\text { moderate grained, about } 80 \% \\
\text { to } 90 \% \text { forming material } \\
\text { basically has crystalline } \\
\text { structure }\end{array}$ \\
\hline Limestone & $\begin{array}{c}\text { Soltangasha, } \\
\text { Dagestan, Russia }\end{array}$ & 201 & $5 \%$ & 2380 & l \\
\hline Amphibolites & Kola & 10000 & $1 \%$ & 2610 & l \\
\hline Granulate & $\begin{array}{c}\text { Saxonian } \\
\text { Granulate } \\
\text { Mountains, } \\
\text { Germany }\end{array}$ & l & $1 \%$ & 2060 & $\begin{array}{l}\text { Quartz } 38 \% \text {, plagioclase } 9 \% \text {, } \\
\text { K-feldspar } 47 \% \text {, biotite } 1 \% \text {, } \\
4 \% \text { granite, mixture of } \\
\text { crystalline and amorphous } \\
\text { structures }\end{array}$ \\
\hline $\begin{array}{l}\text { Pyroxene- } \\
\text { granulate }\end{array}$ & $\begin{array}{c}\text { Saxonian } \\
\text { Granulate } \\
\text { Mountains, } \\
\text { Germany }\end{array}$ & l & $12 \%$ & 3200 & $\begin{array}{c}\text { Granite } 6 \% \text {, clinopyroxene } \\
39 \%, \text { plagioclase } 34 \%, \\
\text { non-transparent minerals } \\
11 \%, \text { orthopyroxene } 9 \%, \\
\text { ambibolb1\%, basically } \\
\text { amorphous structure }\end{array}$ \\
\hline Siltstone & $\begin{array}{c}\text { Dmitrievskoe, } \\
\text { Dagestan, Russia }\end{array}$ & $\begin{array}{l}4570 \sim \\
4574\end{array}$ & $1 \sim 2 \%$ & l & From oil-gas field \\
\hline Dolomite & $\begin{array}{c}\text { Dmitrievskoe, } \\
\text { Dagestan, Russia }\end{array}$ & $\begin{array}{l}4247 \sim \\
4248\end{array}$ & $1 \sim 2 \%$ & I & From oil-gas field \\
\hline Andesite & Dagestan, Russia & 240 & $1 \%$ & 2540 & Quartzite andesite-basalt \\
\hline
\end{tabular}

On the whole, the experimental methods to acquire the thermal conductivities of the rock-soil are relatively time consuming and expensive compared to theoretical ones. The equipment should be placed near the borehole and the soil sample should be acquired for the 
measurement. The obtained results could only be used for local heat exchanger calculation. But relatively high accuracy of the thermal conductivities can be achieved compared with the predictions by the theoretical methods, which will no doubt contribute to the estimation of engineering cost. Supported by the appropriate theories, the experimental tests could provide reliable data for the verification of theoretical predicted results. The experiment is an important and unnegligible research method for the study of the rock-soil effective thermal conductivity.

\section{Concluding remarks}

There are many ways to evaluate the performance of the ground buried heat exchangers before the actual project, which can be classified into theoretical methods and numerical approaches. The theoretical methods including the line source model presented by Ingersoll and Plass (1948), the cylindrical source model presented by Carslaw and Jeager (1959) and other models either based on these two models or developed through other ways. The numerical approaches are usually implemented through the computer software or programming and have been widely used for the estimation of the heat exchangesystem. No matter theoretical or numerical methods, one of the most important parameters that affect the heat transfer performance is the thermal conductivities of different types of rock-soil. Take the one dimensional heat conduction process as an example, the conduction heat flux is (Carslaw and Jaeger, 1959),

$$
q=-\lambda \frac{\partial T}{\partial x}
$$

which indicates that the amount of heat the buried pipe can absorb from the rock-soil mainly depends on the thermal conductivity of the soil and the temperature gradient. It's very important to obtain the thermophysical properties so that the performance of the heat exchange system can be estimated in advance.

Among the above mentioned thermal conductivity determination methods, the theoretical methods are able to make prediction beforehand as they are mainly based on the basic models related to the real soil structure or the existing measurement data. Therefore it would be possible for us to make the estimation before the practical project. Meanwhile, the 
experimental methods provide us with relatively accurate values of the rock-soil properties, while the process could be relatively expensive and time consuming. The two ways should be combined and properly chosen depending on the actual project to achieve better use of the geothermal energy.

\section{References}

Agari, Y., Uno, T., 1986. Estimation on thermal conductivities of filled polymers. Journal of Applied Polymer Science. 32(7), 5705-5712.

Alharthi, A., Lange, J., 1987. Soil water saturation: Dielectric determination. Water Resources Research. 23(4), 591-595.

Alishaev, M. G., Abdulagatov, I. M., Abdulagatova, Z. Z., 2012. Effective thermal conductivity of fluid-saturated rocks: experiment and modeling. Engineering geology. 135, 24-39.

Anand, J., 1971. Thermal conductivity of fluid saturated rocks at elevated pressures and termperatures. University of California, Berkeley.

Anand, J., Somerton, W. H., Gomaa, E., 1973. Predicting thermal conductivities of formations from other known properties. Society of Petroleum Engineers Journal. 13(05), 267-273.

Asaad, Y., 1955. A study of the thermal conductivity of fluid-bearing porous rocks. University of California, Berkeley.

Batchelor, G. K., O'brien, R. W., 1977. Thermal or electrical conduction through a granular material. Proc. R. Soc. Lond. A. 355(1682), 313-333.

Beck, A. E., 1976. An improved method of computing the thermal conductivity of fluid-filled sedimentary rocks. Geophysics. 41(1), 133-144.

Bouguerra, A., 1999. Prediction of effective thermal conductivity of moist wood concrete. Journal of Physics D: Applied Physics. 32(12), 1407.

Buntebarth, G., Rueff, P., 1987. Laboratory thermal conductivities applied to crustal conditions. Rev Brasil Geofisica. 5, 103-109.

Campbell, G. S., Jungbauer Jr, J. D., Bidlake, W. R., Hungerford, R. D., 1994. Predicting the effect of temperature on soil thermal conductivity. Soil Science. 158(5), 307-313.

Carslaw, H. S., Jaeger, J. C., 1959. Conduction of heat in solids. Oxford: Clarendon Press, 1959, 2nd ed.

Carson, J. K., Lovatt, S. J., Tanner, D. J., Cleland, A. C., 2005. Thermal conductivity bounds for isotropic, porous materials. International Journal of Heat and Mass Transfer. 48(11), 2150-2158.

Chen, S. X., 2008. Thermal conductivity of sands. Heat and mass transfer. 44(10), 1241.

Cosenza, P., Guerin, R., Tabbagh, A., 2003. Relationship between thermal conductivity and water content of soils using numerical modelling. European Journal of Soil Science. 54(3), 581-588.

Côté, J., Konrad, J. M., 2005. A generalized thermal conductivity model for soils and construction materials. Canadian Geotechnical Journal. 42(2), 443-458.

Côté, J., Konrad, J. M., 2005. Thermal conductivity of base-course materials. Canadian Geotechnical Journal. 42(1), 61-78.

Dagan, G., 1989. Flow and transport in porous formations. Springer-Verlag, Berlin.

DE Vries, D. A., 1963. Thermal Properties of Soils. Physics of Plant Environment.

Deerman, J. D., 1991. Simulation of vertical U-tube ground-coupled heat pump systems using the cylindrical heat source solution. ASHRAE transactions, 97(1), 287-295. 
Dobson, M. C., Ulaby, F. T., Hallikainen, M. T., El-Rayes, M. A., 1985. Microwave dielectric behavior of wet soil-Part II: Dielectric mixing models. IEEE Transactions on Geoscience and Remote Sensing. (1), 35-46.

Donazzi, F., Occhini, E., Seppi, A., 2010. Soil thermal and hydrological characteristics in designing underground cables. Proceedings of the Institution of Electrical Engineers. 126(6), 506-516.

Dong, Y., McCartney, J. S., \& Lu, N., 2015. Critical review of thermal conductivity models for unsaturated soils. Geotechnical and Geological Engineering. 33(2), 207-221.

Ewen, J., Thomas, H. R., 1987. The thermal probe - a new method and its use on an unsaturated sand. Geotechnique. 37(1), 91-105.

Farouki, O. T., 1982. Evaluation of methods for calculating soil thermal conductivity (No. CRREL-82-8). COLD REGIONS RESEARCH AND ENGINEERING LAB HANOVER NH.

Fricke, H., 1924. A mathematical treatment of the electric conductivity and capacity of disperse systems I. The electric conductivity of a suspension of homogeneous spheroids. Physical Review. 24(5), 575-587.

Friedman, S. P., 1998. A saturation degree - dependent composite spheres model for describing the effective dielectric constant of unsaturated porous media. Water Resources Research. 34(11), 2949-2961.

Friedman, S. P., 2005. Soil properties influencing apparent electrical conductivity: a review. Computers and electronics in agriculture. 46(1-3), 45-70.

Fujii, H., Okubo, H., Nishi, K., Itoi, R., Ohyama, K., Shibata, K., 2009. An improved thermal response test for U-tube ground heat exchanger based on optical fiber thermometers. Geothermics. 38(4), 399-406.

Funnell, R., Chapman, D., Allis, R., Armstrong, P., 1996. Thermal state of the Taranaki basin, New Zealand. Journal of Geophysical Research: Solid Earth. 101(B11), 25197-25215.

Gangadhara Rao, M. V. B. B., Singh, D. N., 1999. A generalized relationship to estimate thermal resistivity of soils. Canadian Geotechnical Journal. 36(4), 767-773.

Gehlin, S. E., Hellstrom, G., 2003. Comparison of four models for thermal response test evaluation. ASHRAE transactions. 109, 131.

Gens, A., Sánchez, M., Guimaraes, L. D. N., Alonso, E. E., Lloret, A., Olivella, S., Villar, M. V., Huertas, F., 2009. A full-scale in situ heating test for high-level nuclear waste disposal: observations, analysis and interpretation. Géotechnique. 59(4), 377-399.

Go, G. H., Lee, S. R., Kim, Y. S., 2016. A reliable model to predict thermal conductivity of unsaturated weathered granite soils. International Communications in Heat and Mass Transfer. 74, 82-90.

Gori, F., Corasaniti, S., 2002. Theoretical prediction of the soil thermal conductivity at moderately high temperatures. Journal of Heat Transfer. 124(6), 1001-1008.

Gori, F., Corasaniti, S., 2003. Experimental measurements and theoretical prediction of the thermal conductivity of two-and three-phase water/olivine systems. International Journal of Thermophysics. 24(5), 1339-1353.

Gori, F., Corasaniti, S., 2013. New model to evaluate the effective thermal conductivity of three-phase soils. International Communications in Heat and Mass Transfer. 47, 1-6.

Hadley, G. R., 1986. Thermal conductivity of packed metal powders. International Journal of Heat and Mass Transfer. 29(6), 909-920.

Haigh, S. K., 2012. Thermal conductivity of sands. Geotechnique. 62(7), 617.

Han, Z., Zhang, S., Li, B., Ma, C., Liu, J., Ma, X., Ju, X., 2018. Study on the influence of the identification model on the accuracy of the thermal response test. Geothermics, 72, 316-322.

Hashin, Z., 1983. Analysis of composite materials - a survey. Journal of Applied Mechanics. 50(3), 481-505.

Hashin, Z., Shtrikman, S., 1962. A variational approach to the theory of the effective magnetic permeability of multiphase materials. Journal of applied Physics. 33(10), 3125-3131.

Hashin, Z., Shtrikman, S., 1963. A variational approach to the theory of the elastic behaviour of multiphase 
materials. Journal of the Mechanics and Physics of Solids. 11(2), 127-140.

Hsu, C. T., Cheng, P., Wong, K. W., 1994. Modified Zehner-Schlunder models for stagnant thermal conductivity of porous media. International journal of heat and mass transfer. 37(17), 2751-2759.

Hsu, C. T., Cheng, P., Wong, K. W., 1995. A lumped-parameter model for stagnant thermal conductivity of spatially periodic porous media. Journal of heat transfer. 117(2), 264-269.

Hwang, S., Ooka, R., Nam, Y., 2010. Evaluation of estimation method of ground properties for the ground source heat pump system. Renewable Energy. 35(9), 2123-2130.

Ingersoll, L. R., Plass, H. J., 1948. Theory of the ground pipe source for the heat pump. ASHVE Trans. 54(3), 339-348.

Johansen, O., 1977. Thermal conductivity of soils. Ph.d.thesis Trondheim University.

Kavanaugh, S. P., 2000. Field tests for ground thermal properties--methods and impact on ground-source heat pump design. Univ. of Alabama, Tuscaloosa, AL (US).

Keller, T., Motschmann, U., Engelhard, L., 1999. Modelling the poroelasticity of rocks and ice. Geophysical prospecting. 47(4), 509-526.

Kersten,Miles S., 1949. Laboratory research for the determination of the thermal properties of soils. Journal of Neurophysiology. 45(4), 667-697.

Kunii, D., Smith, J. M., 1960. Heat transfer characteristics of porous rocks. AIChE Journal. 6(1), 71-78.

Lee, K., 2010. Study on thermal characteristics of backfill materials for horizontal ground heat exchanger [D] Master thesis, Korea University.

Lehmann, P., Stähli, M., Papritz, A., Gygi, A., Flühler, H., 2003. A fractal approach to model soil structure and to calculate thermal conductivity of soils. Transport in porous media. 52(3), 313-332.

Liang, X. G., Ji, X., 2000. Thermal conductance of randomly oriented composites of thin layers. International journal of heat and mass transfer. 43(19), 3633-3640.

Liang, X. G., Qu, W., 1999. Effective thermal conductivity of gas-solid composite materials and the temperature difference effect at high temperature. International Journal of Heat and Mass Transfer. 42(10), 1885-1893.

Lu, S., Ren, T., Gong, Y., Horton, R., 2007. An improved model for predicting soil thermal conductivity from water content at room temperature. Soil Science Society of America Journal. 71(1), 8-14.

Makowski, M. W., Mochlinski, K., 1956. An evaluation of two rapid methods of assessing the thermal resistivity of soil. Proceedings of the IEE-Part A: Power Engineering. 103(11), 453-470.

Maxwell, J. C., 1881. A treatise on electricity and magnetism (Vol. 1). Clarendon press.

McGaw, R., 1969. Heat conduction in saturated granular materials. Highway Research Board Special Report. (103).

McInnes, K. J., 1981. Thermal Conductivities of Soils from Dryland Wheat Reagions of Eastern Washington. MS Thesis, Washington State University.

Mickley, A. S., 1951. The thermal conductivity of moist soil. Transactions of the American Institute of Electrical Engineers. 70(2), 1789-1797.

Miyamoto, T., Annaka, T., Chikushi, J., 2003. Soil aggregate structure effects on dielectric permittivity of an Andisol measured by time domain reflectometry. Vadose Zone Journal. 2(1), 90-97.

Miyamoto, T., Annaka, T., Chikushi, J., 2005. Extended dual composite sphere model for determining dielectric permittivity of andisols. Soil Science Society of America Journal. 69(1), 23-29.

Moench, A. F., Evans, D. D., 1970. Thermal Conductivity and Diffusivity of Soil Using a Cylindrical Heat Source 1. Soil Science Society of America journal. 34(3), 377-381.

Morgensen, P., 1983. Fluid to duct wall heat transfer in duct system heat storage. In Proceedings of the International Conference on Subsurface Heat Storage in Theory and Practice, Stockholm, Sweden. 625-657. 
Nusselt, W., 1916. Die oberflachenkondensation des wasserdampfes. VDI Z. 60, 541-546.

Rees, S. W., Adjali, M. H., Zhou, Z., Davies, M., Thomas, H. R., 2000. Ground heat transfer effects on the thermal performance of earth-contact structures. Renewable and Sustainable Energy Reviews. 4(3), 213-265.

Rohner, E., Rybach, L., Schärli, U., 2005. A new, small, wireless instrument to determine ground thermal conductivity in-situ for borehole heat exchanger design. In Proceedings World Geothermal Congress.

Rzhevsky, Y., Novik, G., 1971. The physics of rocks. Translation and Edited by AA Beknazarov.

Sass, J. H., Lachenbruch, A. H., Munroe, R. J., Greene, G. W., Moses, T. H., 1971. Heat flow in the western United States. Journal of Geophysical Research. 76(26), 6376-6413.

Schapery, R. A., 1968. Thermal expansion coefficients of composite materials based on energy principles. Journal of Composite Materials. 2(3), 380-404.

Sekiguchi, K., 1984. A method for determining terrestrial heat flow in oil basinal areas. Tectonophysics. 103(1-4), 67-79.

Slusarchuk, W. A., Watson, G. H., 1975. Thermal conductivity of some ice-rich permafrost soils. Canadian Geotechnical Journal. 12(3), 413-424.

Smith, W. O., 1942. The thermal conductivity of dry soil. Soil Science. 53(6), 435-460.

Smith, W. O., Byers, H. G., 1939. The Thermal Conductivity of Dry Soils of Certain of the Great Soil Groups 1. Soil Science Society of America Journal. 3[C], 13-19.

Staggs, J. E. J., 2002. Estimating the thermal conductivity of chars and porous residues using thermal resistor networks. Fire Safety Journal. 37(1), 107-119.

Tarnawski, V. R., Gori, F., Wagner, B., Buchan, G. D., 2000. Modelling approaches to predicting thermal conductivity of soils at high temperatures. International Journal of Energy Research. 24(5), 403-423.

Thomas, H. R., He, Y., Ramesh, A., Zhou, Z., Villar, M. V., Cuevas, J., 1994. Heating unsaturated clay—an experimental and numerical investigation. Numerical Methods in Geoteehnical Engineering. AA Balkema, Rotterdam. 181.

Tikhomirov, A., 1968. Conductivity of rocks and their relationship with density, saturation and temperature. Russ. Neft. Khoz. 46(4), 151-161.

Tinga, W. R., Voss, W. A. G., Blossey, D. F., 1973. Generalized approach to multiphase dielectric mixture theory. Journal of Applied Physics. 44(9), 3897-3902.

Tong, F., Jing, L., Zimmerman, R. W., 2009. An effective thermal conductivity model of geological porous media for coupled thermo-hydro-mechanical systems with multiphase flow. International Journal of Rock Mechanics and Mining Sciences. 46(8), 1358-1369.

Van Rooyen, M., Winterkorn, H. F., 1957. Theoretical and practical aspects of the thermal conductivity of soils and similar granular systems. Highway Research Board Bulletin. (168).

Wang, M., Pan, N., 2008. Predictions of effective physical properties of complex multiphase materials. Materials Science and Engineering: R: Reports. 63(1), 1-30.

Wiener, O., 1912. Abhandl. math-phys. K1. k. sachs. Ges. Wissensch. 32, 507.

Woodside, W. M. J. H., Messmer, J. H., 1961. Thermal conductivity of porous media. I. Unconsolidated sands. Journal of applied physics. 32(9), 1688-1699.

Yu, B., Li, B., 2006. Fractal-like tree networks reducing the thermal conductivity. Physical Review E. 73(6), 066302 .

Yu, X., Zhang, Y., Deng, N., Ma, H., Dong, S., 2016. Thermal response test for ground source heat pump based on constant temperature and heat-flux methods. Applied Thermal Engineering, 93, 678-682.

Yun, T. S., Santamarina, J. C., 2008. Fundamental study of thermal conduction in dry soils. Granular matter. 10(3), 197. 
Zehner, P., Schlunder, E. U., 1970. Thermal conductivity of packings at moderate temperatures. Chemie Ingenieur Technik. 42(14), 933-941.

Zimmerman, R. W., 1989. Thermal conductivity of fluid-saturated rocks. Journal of Petroleum Science and Engineering. 3(3), 219-227.

Zimmerman, R. W., 1992. Hashin-Shtrikman bounds on the Poisson ratio of a composite material. Mechanics research communications. 19(6), 563-569. 